\title{
How to Support Innovative Behaviour? The Role of LMX and Satisfaction with HR Practices
}

\author{
Karin Sanders, Matthijs Moorkamp, Nicole Torka, \\ Sandra Groeneveld, Claudia Groeneveld \\ Department of Organizational Psychology and Human Resource Development, University of Twente, \\ Enschede, the Netherlands \\ E-mail: k.sanders@utwente.nl \\ Received November 26, 2009; revised December 14, 2009; accepted December 17, 2009
}

\begin{abstract}
Innovative behaviour of employees refers to a key aspect of organizational effectiveness: the creation, introduction and application of new ideas within a group or organization in order to benefit performance. Using data from a Dutch and German survey in four technical organizations $(n=272)$ we developed and tested two models to explain the relationships between Leader-Member-Exchange (LMX), satisfaction with HR practices (employee influence, flow, rewards and work content) and innovative behaviour. As expected both LMX and satisfaction with HR practices were positively related to innovative behaviour. Furthermore, we found evidence that satisfaction with HR practices mediates the relationship between LMX and innovative behaviour. No significant interaction effects between LMX and satisfaction with HR practices on innovative behaviour were found.
\end{abstract}

Keywords: Innovative Behaviour, Leader Member Exchange, Satisfaction with HR Practices, Technical Organizations

\section{How to Support Innovative Behaviour?}

For contemporary organizations, the financial attractiveness of their products and/or services is mostly not enough to guarantee sustainable survive: goods also have to be of high-quality and preferably unique $[1,2]$. Uniqueness refers to innovation: "the development and implementation of new ideas by people" [3]. It is claimed that innovative behaviour of employees defined as the creation, introduction and application of new ideas within a group or organization in order to benefit performance $[4,5]$ is crucial for the long-time survival of organizations [3,6-9].

Given the importance of innovation, there is a growing interest among scholars trying to answer the question why and under which circumstances employees express innovative behaviour within their organization. To gain such critical employee contributions, scholars argue that the development and implementation of Human Resource Management (HRM) is vital [10]. In general HRM is defined as the management of people and workplace to achieve competitive advantage and involves both HR professionals and (line) management. Although a lot of research has been done in the last two decades, and strategic HRM researchers have converged in their belief that HRM is associated with organizational outcomes, the understanding of the "HRM-performance" relationship, including innovative behaviour is still open to question [11].

In stead of the written HR practices, such as selection and recruitment, performance appraisal, and pay (for performance) attention is moved to the perception of employees regarding the HR practices in a firm. Employees' perceptions of HR practices are likely to precede employee behaviour links in the causal chain: to exert their desired effect on employee behaviour, HR practices first have to be perceived and interpreted subjectively by employees in ways that will engender behavioural reactions $[11,12]$. And, as we know from psychology that people perceive reality differently, we can expect that employees interpret HR practices differently. In this study, we focus on employees' satisfaction with HR practices [13,14]. Because satisfaction with HR practices can be seen as a facet of job satisfaction we examine the relationship between satisfaction with HR practices and job satisfaction as well.

When including employees' satisfaction with HR practices, the role of the direct supervisor can not be underestimated. Many companies delegate operational HRM to those who lead employees directly [10] and as a 
result several key HR administrative tasks-hiring, performance management and compensation - have been devolved to line managers [10]. Since supervisors have some degrees of freedom in dealing with these practices, their decisions and behaviours can be seen as major antecedents of employee attitudes and behaviours. LeaderMember-Exchange (LMX) theory suggests that leaders do not use the same style in dealing with all subordinates, but develop a different relationship with each subordinate on a dyadic basis [15-18]. To date, despite agreement on the importance of the relationships employees have with their supervisor (e.g. [20]), relatively little has been done to study the relationship between LMX and innovative behaviour (see for exceptions [20-22]).

This study contributes to the filling of the knowledge gap related to innovative behaviour in three ways. First, in stead of the (formal) HR practices as described by HR managers or direct supervisors, we focus on the satisfaction employees have regarding the HR practices. Second, since it can be assumed that both employees' satisfaction with HR practices and LMX influence innovative behaviour, we consider the relationship between satisfaction with HR practices and LMX on innovative behaivour. Third, in this study we relate a single-item measurement for general job satisfaction to satisfaction with HR practices. Consequently, using survey data from 272 medium to high-educated technical employees from a Dutch and three German industrial companies, we formulated the research question as follows: How can the relationships between LMX, satisfaction with HR practices, and innovative behaviour be explained?

\subsection{Satisfaction with HR Practices and Innovative Behaviour}

Beer et al. [13] distinguished four HR practices: employee influence, human resource flow, rewards, and work systems. Employee influence refers to a process that allows employees to exercise influence over their work and the conditions under which they work. Human resource flow refers to issues of recruitment, selection, development and ending the contract of organizational members. Rewards are concerned with how employees are rewarded for their work. They include monetary rewards such as pay, bonuses and profit sharing, and non-monetary rewards such as holidays and health insurance. Work systems refer to a particular combination of job tasks, technology, skills, management style and personnel policies and practices. Given the sample of this study - technicians, we separate primary (monetary) from secondary (non-monetary) rewards and refer to work content as work systems.

Innovative behaviour refers to discretionary employee behaviour, behaviour that goes beyond prescribed role expectations and is not directly or explicitly recognized by any formal reward system $[23,24]$. The link between employees' satisfaction and innovative behaviour as a discretionary behaviour can be explained by social exchange theory [25]. Reciprocity lies at the heart of the social exchange perspective $[26,27]$. Economic exchange refers to employment relationships where the conditions of employment are specified and "fixed quid pro quo" is the nature of exchange: a fair day's pay for a fair day's work. Social exchange refers to relationships that entail unspecified future contributions, inducements and obligations and allows parties to reciprocate through discretionary behaviours $[28,29]$.

Employees' satisfaction can be seen as an important predictor of discretionary behaviours like innovative behaviour as theory suggests that whether employees give their efforts wholeheartedly to the organization and produce up to their potential depends to a large part on the way they feel about their job and work environment (e.g. $[21,22,30])$. Therefore, the norm of reciprocity is important in explaining discretionary behaviour in organizations. This line of reasoning assumes that satisfaction with HR practices is viewed by employees as organization's commitment towards them which is then reciprocated back to the organization by employees through positive behaviours, like innovative behaviour $[12,14]$. Hence, this means that we can formulate our first hypothesis: satisfaction with HR practices is positively related to innovative behaviour (Hypothesis 1).

\subsection{Leader Member Exchange (LMX) and Innovative Behaviour}

The basic premise of LMX theory is that leaders establish higher quality exchanges with some of their followers (in-group members) while with other followers leaders rely more on the terms of employment in forging exchanges (out-group members). Research suggests that the quality of the exchanges between employees and their leaders are predictive of attitudinal job outcomes. Examples of attitudinal outcomes which are related to LMX are satisfaction, leader support and organizational commitment (e.g. [17,20,31]). Sanders and Schyns [27] provide evidence that workers' perceptions of the helpfulness of their supervisor are positively related to their willingness to show discretionary behaviour like cooperative behaviours and assisting co-workers. Low- quality exchange relationships, on the other hand, are characterized by more formal, role-defined interactions that result in hierarchy-based downward influence and distance between the parties [32].

Prior research has found that LMX is related to innovative job performance [20-22]. Janssen [4] found evidence that employees responded more innovatively to higher levels of job demands when they perceived that their efforts were fairly rewarded by their leader. This 
means that employees who perceive a fair balance between supervisor's inducements relative to their work efforts will respond with more innovative behaviour. Referring back to social exchange theory additional arguments can be derived for a relationship between LMX and innovative behaviour. Employees personify the organization since everything an organization does, it does through human beings. Direct supervisors can act as organizational agents. Employees tend to view actions by agents of the organization as actions of the organization itself [33]. Therefore, they reward favourable supervisor treatment with desired behaviours. Hence, we can formulate our next hypothesis: LMX is positively related to innovative behaviour (Hypothesis 2).

\subsection{Satisfaction with HR Practices, LMX and Innovative Behaviour}

In general, two lines of reasoning related to the relationships between satisfaction with HR practices, LMX, and innovative behaviour can be found in literature. The first states that satisfaction with HR practices mediates the relationship between LMX and innovative behaviour: satisfaction with HR practices can explain the relationship between LMX and innovative behaviour [17]. The second states that the interaction between satisfaction with HR practices and LMX relates to innovative behaviour: LMX and satisfaction with HR practices stimulate each other and this leads to more innovative behaviour [12].

\subsubsection{Satisfaction with HR Practices as a Mediator}

Positive leader experiences and expectations appear to be associated with favourable leader behaviour towards followers such as the assignment of challenging tasks, distribution of rewards, and constructive feedback (e.g. $[34,35])$. Moreover, research on Leader-Member-Exchange (LMX) shows that the quality of the relationship between supervisor and subordinate strongly impacts employee perceptions concerning the quality of HR practices (e.g. [36,37]). For example, employees' satisfaction of influence will be shaped fundamentally by their personal experience with their supervisor. Furthermore, LMX is related to the job satisfaction of employees [17]. Given that members in high quality dyads perceive more favourable treatment than members in low quality dyads it is not surprisingly that the former have been found to be more satisfied with their jobs than the latter. This means that we can expect that LMX is positively related with satisfaction with $\mathrm{HR}$ practices and satisfaction with HR practices are positively related to innovative behaviour. Hence we formulate the following hypothesis: satisfaction with HR practices mediates the relationship between LMX and innovative behaviour (Hypothesis 3).

\subsubsection{Interaction between Satisfaction with $H R$ Practices and LMX [47]}

Bowen and Ostroff [12] suggest that leadership behaviour and HR practices, in terms of a high HR system, can stimulate each other and increase the willingness to show discretionary behaviour. Thus, the quality of HR practices as perceived by the employees is not necessarily perceived as a consequence of line management behaviour or responsibility. In this way satisfaction with HR practices is regarded as a context within which individuals function. In commenting on contextualization in organizational behaviour research Rousseau and Fried argue that the explicit addressing of contextual factors is necessary for enhancing the comprehensiveness and creativity of research findings [47]. In terms of LMX and satisfaction with HR practices this means that satisfaction with HR practices can be seen as a context in which the relationship between LMX and innovative behaviour is embedded. We can also provide an alternative argument for this interaction effect of satisfaction with HR practices and LMX. Not all direct supervisors have responsibilities and power on the HR practices of their subordinates. In such a situation, HR practices are shaped outside the leadermember relationship [38]. Hence we formulate the following hypothesis: the interaction between satisfaction with HR practices and LMX is positively related to innovative behaviour (Hypothesis 4).

\section{Method}

\subsection{Sample}

The survey included 272 employees in four Dutch and German technical organizations (response rate for the four organizations varies between 42 to of $66 \%$ ). Participation was voluntary for all employees, and confidentiality was assured. Respondents with supervisory tasks were excluded from this sample.

Of these 272 respondents 200 are men (74\%). 75 Employees $(52 \%)$ are between 25 and 35 years old and 45 employees $(31 \%)$ between 35 and 45 years old. 89 respondents $(62 \%)$ worked less than 5 years within the organization, 29 respondents $(20 \%)$ between 5 and 10 years and 26 respondents (18\%) worked ten years or longer in the organization. Finally, 73 respondents $(27 \%)$ finished their secondary vocational education. 76 respondents $(28 \%)$ finished their higher vocational education and $41(15 \%)$ achieved their university degree.

The four organizations differ in the number of respondents (between 32 and 135) and in terms of the age of the employees $(\mathrm{F}(3,265)=19.92, \mathrm{p}<.01)$, education $(\mathrm{F}(3,265)=4.74 ; \mathrm{p}<.01)$ and tenure within the organization $(\mathrm{F}(3,265)=18.88, \mathrm{p}<.01)$. The organizations did not differ in terms of sex distribution within the organization $\left(\chi^{2}(3)=2.37\right.$, n.s. $)$ 


\subsection{Procedure}

All employees had access to computers. Employees received an e-mail with a link to the questionnaire. The e-mail contained supplementary information about the subjects that the questionnaire contained and the utmost confidence in which respondent answers are treated. Respondents had a week time to fill out the questionnaires. The introduction letter of the questionnaire contained supplementary information to motivate and inform the respondent about the questionnaire.

\subsection{Measurements}

Following Janssen [4] innovative behaviour is measured by a nine-item scale, an example being "How often does it occur that you create new ideas for difficult issues?" Respondents were asked on a five-point-scale ranging from 1 "never" till 5 "always" to give their opinion. Given the high inter-correlations between the idea generation, idea promotion, and idea realization subscales (all above .82) these subscales were conceived to combine additively to create an overall scale of innovative work behaviour. The scale was found reliable (Cronbach's $\alpha=.92$ ).

Leader-Member-Exchange was measured using the twelve-item scale of Grean et al. [34]. Examples of this scale are "My supervisor would come to my defence if I were 'attacked' by other", and "My supervisor is a lot of fun to work with". The response format was a five-point scale ranging from 1 "disagree completely" till 5 "agree completely". The scale was found reliable (Cronbach's $\alpha=.92$ ).

For the different aspect of satisfaction with HR practices we combined previous scales from Torka [38], and Van den Heuvel. For all items of the HR practices the response formats ranged from 1 "very dissatisfied" till 5 "very satisfied". For measuring satisfaction with employee influence two sub-dimensions were distinguished: employee voice (an example: "How satisfied are you with the extent to which your opinion is sought regarding (changes in) your job?") and participation in decision making (an example: "How satisfied are you with the extent to which you can co-decide on (changes in) your job?"). Each dimension was measured with three items. Although these two sub-dimensions are theoretically fundamental different, given the high inter-correlations between these two sub dimensions, they are taken together. Moreover the different items of the two sub-dimensions loaded on one factor. The scale turned out to be sufficient (Cronbach's $\alpha=.93$ ).

Satisfaction with HR flow was measured using a five item-scale excluding outflow issues. An example of this scale is: "How satisfied are you with the guidance you were given during the first six months of your employ- ment at this organization?" The scale turned out to be sufficient (Cronbach's $\alpha=.76$ ). Satisfaction with primary rewards was measured using a nine item-scale. An example of this scale is: "How satisfied are you with your salary". The scale turned out to be sufficient (Cronbach's $\alpha=.95$ ). Satisfaction with secondary rewards was measured using a five item-scale. An example of this scale is: "How satisfied are you with the wide-ranging package of secondary terms of employment". The scale turned out to be sufficient (Cronbach's $\alpha=.94)$. Satisfaction with work content was measured using an eight item-scale. An example of this scale is: "How satisfied are you with the variation offered by your job?" The scale turned out to be sufficient (Cronbach's $\alpha$ $=.86$ ).

Furthermore the respondents were asked to give a score (1 till 10) for their job satisfaction in general. The average of this score is $7.08(\mathrm{SD}=2.05)$.

\subsection{Analyses}

To control for the possibility that socio-demographic differences in the predictor and outcome variables might lead to spurious relationships, gender $(0=$ male, $1=\mathrm{fe}-$ male), age (year of birth was recoded), educational qualifications $(1$ = secondary education, 2 = higher education, and $3=$ university), and tenure in the organization (number of years) were entered as control variables in the analysis. Moreover, we controlled for country (location of the organization) and for nationality of the employees $(1=$ German, $2=$ Dutch, and $3=$ other $)$. Because these variables did not have a significant effect, nor did they influence the other effects these effects are not presented in the Tables.

Because all variables in this study were based on self reports and collected at a single point in time, Harman's one factor test was used to investigate the potential influence of common method variance. Therefore, the items of the dependent and independent variables were submitted to a principal components analysis with oblique rotation. The results show seven factors (innovative behaviour, LMX, and satisfaction with five HR practices) with an "eigenvalue" greater than 1 , accounting for 49.38 percent of the variance. Each item "loaded" on its appropriate factor, with primary loadings exceeding .40 and cross-loadings lower than .25 . This strongly suggests that the measures of the predictors are independent of the dependent variable and that common method bias is likely to have a very limited effect.

Given our mean interest to explain employee-to-employee difference in innovative behaviour we decided to test the hypotheses with an ordinary regression analyses on individual level and not to use multi level analyses, although the data is nested within four organizations. Moreover the intra class correlation of innovative be- 
haviour is low: .02, meaning that only two percent of the variance of innovative behaviour can be explained by differences between the four organizations (in other terms: 98 percent of the variance of innovative behaviour occurs within organizations). Moreover, both LMX and satisfaction with HR practices can be seen as individual characteristic in nature.

To test the mediating effect $(\mathrm{H} 3)$, in reference to the method of Baron and Kenny, we first checked whether the effect of LMX on satisfaction with HR practices was significant (first part of Table 3), and furthermore if the effect of LMX on innovative behaviour is significant and decreased or disappeared when adding the mediator (satisfaction with HR practices) to the model (second part of Table 3). To test the interaction-effect of satisfaction with HR practices and LMX (H4) the Aiken and West and Cohen et al. method was used (Table 3).

\section{Results}

\subsection{Descriptive Statistics and Correlations}

Table 1 presents means and standard deviations, and zero-order Pearson correlations for the variables investigated in this study. Regarding the satisfaction with the HR practices, the respondents are more satisfied with work content than with the other HR practices (influence: $\mathrm{t}(244)=12.25, \mathrm{p}<.01$; flow $(\mathrm{t}(260)=8.340 ; \mathrm{p}<.01)$, primary rewards: $\mathrm{t}(257)=17.02 ; \mathrm{p}<.01$; and second rewards: $\mathrm{t}(243)=6.62, \mathrm{p}<.01)$. In addition, employees are more satisfied with influence and flow than with rewards $(\mathrm{t}(243)=7.95, \mathrm{p}<.01 ; \mathrm{t}(246)=7.97 ; \mathrm{p}<.01)$.

Innovative behaviour is positively related to LMX ( $\mathrm{r}$ $=.25, \mathrm{p}<.01)$, satisfaction with work content $(\mathrm{r}=.26$, $\mathrm{p}<.01)$, and satisfaction with influence $(\mathrm{r}=.30 ; \mathrm{p}<.01)$. Moreover innovative behaviour is positively related with level of education $(\mathrm{r}=.16, \mathrm{p}<.01)$. LMX is positively related to all forms of satisfaction with HR practices except secondary rewards: influence $(\mathrm{r}=.47, \mathrm{p}<.01)$, flow $(\mathrm{r}=.30, \mathrm{p}<.01)$, primary rewards $(\mathrm{r}=.28, \mathrm{p}<.01)$ and work content $(\mathrm{r}=.42, \mathrm{p}<.01)$. Furthermore, LMX is negatively related to age $(\mathrm{r}=-.21, \mathrm{p}<.01)$ and tenure $(\mathrm{r}=$ $-.34, p<.01)$. All of the different forms of satisfaction with HR practices are positively interrelated to each other, and to the overall measurement of job satisfaction.

\subsection{Facet and Global Measures of Satisfaction}

To examine the relationship between the satisfaction with the HR practices and the overall job satisfaction we conducted a regression analysis with the overall job satisfaction as dependent variable and the control variables in the first model and satisfaction with the HR practices as the independent variables in the second model (see Table 2). While age is positively related to the overall job satisfaction $(\beta=.24, \mathrm{p}<.01)$, tenure and education level are negatively related to the overall job satisfaction (respectively $\beta=-.19 ; \mathrm{p}<.05 ; \beta=-.15, \mathrm{p}<.05$ ). All significant effects disappeared however when satisfaction with the HR practices were added to the model, meaning that satisfaction with HR practices mediates the relationship between characteristics of the employees and overall satisfaction. Related to the satisfaction with HR practices the results show that especially satisfaction with work content $(\beta=.60 ; p<.01)$, and to a lesser extent satisfaction with flow $(\beta=.13 ; \mathrm{p}<.05)$ and primary rewards $(\beta=.13, \mathrm{p}<05)$ are related to the overall job satisfaction. The individual characteristics and the satisfaction with the HR practices explain 55 percent of the total variance of the overall job satisfaction.

\subsubsection{Test of the Hypothesized Models}

The results of the regression analysis to test the different hypotheses are reported in Table 3 . In the first model the individual variables are added (Step 1). Sex is negative related to innovative behaviour (men report more innovative behaviour; $\beta=-.20 ; p<.01)$, and education level is positive related to innovative behaviour $(\beta=.17 ; \mathrm{p}<.01)$. H1 predicted a positive relationship between LMX and innovative behaviour. Given the beta of LMX in Model 2 (second part of the Table, Step 2; $\beta=.19, \mathrm{p}<.01$ ), H1 can be confirmed.

H2 predicted a positive relationship between satisfaction with the HR practices and innovative behaviour. In line with this hypothesis positive relationships are found for satisfaction with influence $(\beta=.27 ; \mathrm{p}<.01)$, and work content $(\beta=.20, p<.01)$. Contrary to the hypothesis satisfaction with primary rewards show a negative relationship with innovative behaviour $(\beta=-.19 ; \mathrm{p}<.01)$. No significant effects were found for satisfaction with flow and secondary rewards. This means that $\mathrm{H} 2$ can be confirmed for satisfaction with influence and work content yet have to be rejected for satisfaction with primary rewards, and can not be confirmed for satisfaction with flow and secondary rewards.

To test the mediating effect of satisfaction with HR practices in the relationship between LMX and innovative behaviour (H3) first the relationship between LMX on the satisfaction with HR practices are examined (first part of Table 3). Although the effect of LMX on satisfaction with secondary rewards is only marginal $(\beta=.12$; $\mathrm{p}<.10$ ) the results show that LMX is positive related to the HR practices, meaning that the first part of the mediating effect can be confirmed. Furthermore, the effects for the individual characteristics differ for the forms of satisfaction. While women are more satisfied with the primary rewards, men are more satisfied with the work content. And while education level is positively related to satisfaction with flow, it is negatively related to satisfaction with primary rewards and work content. In ge- 
Table 1. Means, Standard deviations and zero order Pearson Correlations for the variables used in our analysis.

\begin{tabular}{|c|c|c|c|c|c|c|c|c|c|c|c|c|c|}
\hline & $\mathrm{M}$ & SD & 1. & 2. & 3. & 4. & 5. & 6. & 7. & 8. & 9. & 10. & 11. \\
\hline $\begin{array}{l}\text { 1. Innovative behav- } \\
\text { iour }\end{array}$ & 3.15 & .75 & & & & & & & & & & & \\
\hline 2. LMX & 3.67 & .73 & $.25 * *$ & & & & & & & & & & \\
\hline 3. Influence & 3.20 & .68 & $.30 * *$ & $.47 * *$ & & & & & & & & & \\
\hline 4. Flow & 3.38 & .77 & .09 & $.30 * *$ & $.57 * *$ & & & & & & & & \\
\hline 5. Primary Rewards & 2.79 & .80 & -.06 & $.28 * *$ & $.44 * *$ & $.29 * *$ & & & & & & & \\
\hline 6. Secondary Rewards & 2.78 & .88 & .08 & .12 & $.28^{*}$ & $.14^{*}$ & $.30 * *$ & & & & & & \\
\hline 7. Content & 3.71 & .67 & $.26 * *$ & $.42 * *$ & $.55^{* *}$ & $.57 * *$ & $.32 * *$ & $.15^{* *}$ & & & & & \\
\hline 8. Job satisfaction & 7.08 & 2.05 & $.17 *$ & $.31 * *$ & $.48 * *$ & $.54 * *$ & $.38 * *$ & $.20 * *$ & $.69 * *$ & & & & \\
\hline 9. Sex & .26 & .44 & -.08 & $.16^{* *}$ & $.16^{* *}$ & .06 & $.17 * *$ & -.06 & $-.10 *$ & .03 & & & \\
\hline 10. Tenure & 2.27 & 1.27 & -.05 & $-.34 * *$ & $-.15 * *$ & -.16 & $-.13 *$ & -.05 & $-.12 *$ & -.04 & -.11 & & \\
\hline 11. Age & 2.38 & 1.02 & .07 & $-.21 * *$ & -.09 & -.08 & .04 & .07 & .09 & .07 & -.11 & $.65^{* *}$ & \\
\hline 12. Education & 1.88 & .64 & $.16^{* *}$ & .09 & -.09 & -.06 & $.14 *$ & .05 & -.04 & .09 & $.18 * *$ & -.06 & .11 \\
\hline
\end{tabular}

Table 2. Results of a regression analysis with job satisfaction as dependent variable and satisfaction with the HR practices as independent variables.

\begin{tabular}{lcc}
\hline Variables & Model 1 & Model 2 \\
\hline Control variables & & .08 \\
Sex & $-.19^{*}$ & .07 \\
Tenure & $.24^{* *}$ & .08 \\
Age & $-.15^{*}$ & -.02 \\
Education & & -.06 \\
Satisfaction with HR practices & & .01 \\
Influence & & $.13^{*}$ \\
Flow & & $.13^{*}$ \\
Primary rewards & & $.08^{+}$ \\
Secondary rewards & .04 & $.60^{* *}$ \\
Work content & & .55 \\
Explained variance & & \\
\hline
\end{tabular}

Table 3. Results of regression analysis with innovative behaviour as dependent variables.

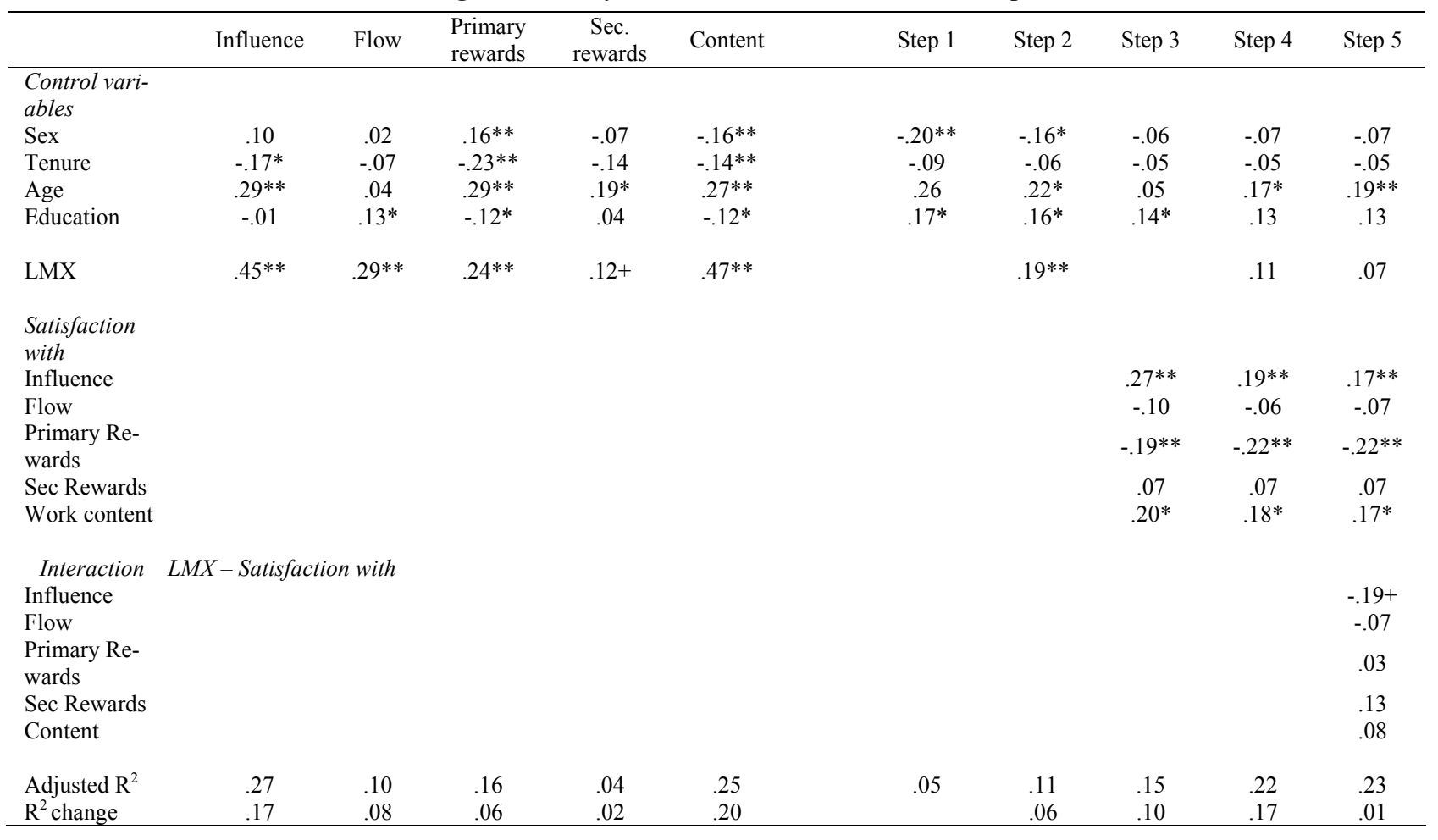

$* *=\mathrm{p} \leq .01 ; *=\mathrm{p} \leq .05$; 
neral, tenure is negatively related, and age is positively related to satisfaction with the HR practices.

To test if satisfaction with HR practices mediates the relationship between LMX and innovative behaviour, satisfaction with the HR practices is added to Step 2 (see Step 4; second part of the Table). The results show that the significant effect of LMX disappeared (from $\beta=.19$, $\mathrm{p}<.01$ to $\beta=.11$, n.s.), while some of the HR practices show a significant effect (influence: $\beta=.19$; $\mathrm{p}<.01$; primary rewards: $\beta=-.22, p<.01$, and work content: $\beta=.20$, $\mathrm{p}<.01$ ). This means that we can confirm H3: satisfaction with HR practices mediates the relationship between LMX and innovative behaviour.

In addition we test if LMX mediates the relationship between satisfaction with HR practices and innovative behaviour. Comparing Step 4 with Step 3 no significant effect of the satisfaction with HR practices disappeared when LMX is added, nor did LMX show a significant effect.

To test H4 the interaction effects between LMX and satisfaction with HR practices were added to the model (Step 5). None of interaction effects were found significant. This means that H4 can not be confirmed.

\section{Discussions}

The aim of this article was to answer the question if satisfaction with HR practices and Leader-Member-Exchange (LMX) can explain innovative behaviour, and, if so, to examine how satisfaction with HR practices and LMX are related to innovative behaviour. To clarify these relationships we used data from employees working in technical organizations in the Netherlands and Germany. The results of this survey study lead to the following conclusions. First, satisfaction with HR practices, especially satisfaction with influence and work content are positively related to innovative behaviour; satisfaction with primary rewards is however negatively related to innovative behaviour. Second, LMX is positively related to innovative behaviour. Third, in stead of an interaction effect between satisfaction with HR practices and LMX, satisfaction with HR practices mediates the relationship between LMX and innovative behaviour. Furthermore, we found that satisfaction with influence, primary rewards and especially work content are positively related to general job satisfaction.

Next to the conclusions the results demand answers for two issues: the effect of satisfaction with primary rewards on innovative behaviour and the relationship between the HR practices and general job satisfaction. First, in contrast to our hypotheses we found a negative effect of satisfaction with primary rewards to innovative behaviour: the more employees are satisfied with their salary the less innovative behaviour they show. Moreover, satisfaction with primary rewards was positively related to the overall job satisfaction. In other words, satisfaction with pay influences discretionary behaviours negatively, but employees' general satisfaction positively.

One explanation might be related to our measurements. Tremblay et al. [41] conclude that the use of a general pay satisfaction measure could influence conclusions on pay satisfaction and its correlates. We measured overall pay satisfaction composed of the three pay satisfaction dimensions. The authors suggest to differentiate between three dimensions: 1) compensation amount - satisfaction with the amount of individual compensation considering work done and effort put in; 2) compensation comparisonsatisfaction with individual compensation relative to other people and other jobs (distributive justice concerning pay or pay equity; $[39,40]$ ) and compensation practices-satisfaction with compensation increase policies and the criteria employed in determining compensation structure. Research shows that distributive justice perceptions play a more important role for employees' attitudes than procedural justice in job satisfaction and satisfaction with the organization [41]. Therefore, we assume that social comparisons (distributive justice) concerning pay may predict innovative behaviour better than self-comparisons and general measures of pay satisfaction.

We can present two alternative explanations for the negative relationship between pay satisfaction and innovative behaviour. First, pay can not replace good management. In other words, when employees are satisfied with pay, but other organization inducements lack such as job characteristics tailored to employee needs, management does not offer the motivators necessary for discretionary behaviour. Second and related to Herzberg's theory, Deci suggests that compensation may only influence performance strongly for those individuals who have high endorsement of money ethic. In contrast, extrinsic rewards such as money may also undermine people's intrinsic motivation to a task [42]. Considering the last-mentioned explanation, the sample of our study consists of medium to high educated technicians, often referred to as knowledge workers. Several authors argue that for knowledge workers the work content is most important in work life $[43,44]$ and our results show that for this occupational group the work content is one of the two HR practices important for innovative behaviour. Thus, knowledge workers are foremost intrinsically motivated and for them (over) compensation may poison the willingness for discretionary behaviour turning their preliminary relational psychological contract into a transactional contract braking extra-role behaviour [28].

The other HR practice important for technical employees' innovative behaviour is influence or voice: a process that allows employees to exercise influence over their work and the conditions under which they work. Since our results show that not all HR practices influence 
medium to high-educated employees in their innovative behaviour, we assume that for them voice concerning different HR practices is not equal important. The results suggest that voice concerning the work content is most important. Therefore, future research on HR practices should include employees' opportunities for voice taking into account different practices as well as include different occupational groups in general [14].

Earlier studies collected data from single respondents in each firm - mostly HR managers or other top managers - and were related to written HR practices within a firm. This approach has been widely criticized because of its subjectively character, and of its focus on intended in stead of espoused HR practices as perceived by employees: one of the explanations for the inconclusive results of studies on the HRM-performance link in general (e.g. [45]). We can assume that employee attitudes are influenced not so much by the way these HR practices are intended to operate as by the way they are actually implemented by line managers on a day-to-day basis [14]. Therefore in this study we focused on the employees' experience of the HR practices because we know that behaviour is mostly driven by employee interpretations in stead of practices as described by managers.

Our data showed that general job satisfaction is not in the same way related to the HR practices: general job satisfaction is related to satisfaction with influence and with primary rewards and is especially related to satisfaction with work content. The results show that it makes sense to separate the different HR practices. After all, researchers and managers want to gain insight in the impact of different facets of HRM on general job satisfaction. Given our results it can be expected that satisfaction of HR practices and job satisfaction differ in their antecedents and in their consequences. More research is needed to the different facets of job satisfaction and their interrelationships.

The practical implication of this study is that in order to improve employees' innovative behaviour within technical organizations attention should be paid to the managers and the relationships they have with the subordinates. This study shows that LMX is positively related to satisfaction with HR practices, and satisfaction with HR practices is positively related to innovative behaviour. The relationships managers have with their employees can be improved by providing a formal and informal training for managers to improve their leadership qualities, and by making them aware of the impact of their relationship with the employees. Research shows that leaders with different backgrounds need other kinds of training to become effective [46].

On the other hand, research shows that the perception of employees of the leadership is not only influenced by the manager yet is influenced by characteristics of the employees as well [27]. For instance, the more the em- ployee and the manager are alike in terms of personality, the higher the relationship between employee and manager is qualified by the employees. This means that attention can be paid to the similarity between managers and subordinates when employees are hired and teams are created. Furthermore employees can become aware that they can influence their perception of and their relationship with the manager.

This study has limitations and strengths. First we have to make a causality remark due to the cross-sectional limitations. Future research could be extended but also deepened by a qualitative part: collecting in-depth information on HR practices as perceived by top-managers, supervisors and different subordinates. Second a social desirability in the answers of the respondents should be taking into account as a possible limitation. Furthermore, research shows that the career commitment of knowledge workers moderates the relationship between company practices and organizational commitment as well as turnover intention. Therefore, further research should include commitment to work, career and commitment to the organization into account and should examine the relationships between commitment and innovative behaviour [20].

Strength of this study is that we focused on LMX and satisfaction with HR practices, and how these are related to innovative behaviour. It appeared that LMX and satisfaction with work content and with influence had the strongest influence in explaining innovative behaviour. Furthermore, the results show that satisfaction with HR practices mediates the relationship between LMX and innovative behaviour, meaning that the relationships the supervisor have with his or her subordinates have, via satisfaction with HR practices, an impact on innovative behaviour of employees.

\section{Acknowledgements}

The authors would like to thank Suzanne Siep, Thomas Kowalewski, Britta Lange, Britta Ruschoff and Maria Demir (master students of psychology; University of Twente, the Netherlands) for part of the data collection.

\section{References}

[1] P. T. Bolwijn and T. Kumpe, "Manufacturing in the 1990s - productivity, flexibility and innovation," Long Range Planning, Vol. 23, pp. 44-57, 1990.

[2] L. J. Harrison-Walker, "The measurement of word-ofmouth communication and an investigation of service quality and customer commitment as potential antecedents," Journal of Service Research, Vol. 4, pp. 60-75, 2001.

[3] J. L. Pierce and A. L. Delbecq, "Organization structure, individual attitudes and innovation," Academy of Man- 
agement Review, Vol. 2, pp. 27-37, 1977.

[4] O. Janssen, "Job demands, perceptions of effort-reward fairness and innovative work behaviour," Journal of Occupational and Organizational Psychology, Vol. 73, pp. 287-302, 2000.

[5] T. Amabile, "A model of creativity and innovation in organizations," In: B. M. Staw and L. L. Cummings. (Eds.) Research in organization behaviour. Greenwich, CT: JAI Press, pp. 187-209, 1988.

[6] R. Kanter, "When a thousand flowers bloom," In: B. M. Staw and L. L. Cummings (Eds.). Research in organization behaviour. Greenwich, CT: JAI Press, pp. 169-211, 1988.

[7] M. A. West and J. L. Farr, "Innovation at work: Psychological perspectives," Social Behaviour, Vol. 4, pp. 15-30, 1989.

[8] G. R. Oldham and A. Cummings, "Employee creativity: Personal and contextual factors at work," Academy of Management Journal, Vol. 39, pp. 607-634, 1996.

[9] A. H. Van de Ven, "Central problems in the management of innovation," Management Science, Vol. 32, pp. 590-607, 1986.

[10] D. E. Guest, "Human resource management and industrial relations," Journal of Management Studies, Vol. 24, pp. 503-521, 1987.

[11] L. H. Nishii, D. P. Lepak, and B. Schneider, "Employee attributions of the 'why' of HR practices: Their effects on employee attitudes and behaviours, and customer satisfaction," Personnel Psychology, Vol. 61, pp. 503-545, 2008.

[12] D. E. Bowen and C. Ostroff, "Understanding HRM-firm performance linkages: The role of the 'strength' of the HRM system," Academy of Management Review, Vol. 29, pp. 203-221, 2004.

[13] M. Beer, B. Spector, P. R. Lawrence, D. Q. Mills, and R. E. Walton, "Managing human assets," New York: The Free Press, 1984.

[14] N. Kinnie, S. Hutchinson, J. Purcell, B. Rayton, and J. Swart, "Satisfaction with HR practices and commitment to the organization: Why one size does not fit all," Human Resource Management Journal, Vol. 15, pp. 9-29, 2005.

[15] G. B. Graen, R. C. Liden, and W. Hoel, "Role of leadership in the employee withdrawal process," Journal of Applied Psychology, Vol. 67, pp. 686-872, 1982.

[16] G. B. Graen and T. A. Scandura, "Toward a psychology of dyadic organizing," Organizational Behaviour, Vol. 9, pp. 175-208, 1987.

[17] C. R. Gerstner and D. V. Day, "Meta-analytic review of Leader-Member-Exchange theory: Correlates and construct issues," Journal of Applied Psychology, Vol. 82, pp. 827-844, 1997.

[18] G. B. Graen and M. Uhl-Bien. "Relationship-based approach to leadership: Development of Leader-MemberExchange (LMX) theory of leadership over 25 years: Applying a multi-level multi-domain perspective," Leadership Quarterly, Vol. 6, pp. 219-247, 1995.
[19] T. Elkins and R. T. Keller, "Leadership in research and development organizations: A literature review and conceptual framework," The Leadership Quarterly, Vol. 14, pp. 587-606, 2004.

[20] R. Basu and S. G. Green, "Leader-Member-Exchange and transformational leadership: An empirical examination of innovative behaviours in leader-member dyads," Journal of Applied Social Psychology, Vol. 27, pp. 477-499, 1997.

[21] S. G. Scott and R. A. Bruce, "Determinants of innovative behaviour: A path model of individual innovation in the workplace," Academy of Management Journal, Vol. 37, pp. 580-607, 1994.

[22] S. G. Scott and R. A. Bruce, "Innovation and the LMX connection: Getting a foothold on relationships that work," IEEE Journal, Vol. 17, pp. 10-11, 1994.

[23] T. S. Bateman and D. W. Organ, "Job satisfaction and the good soldier: The relationship between affect and employee citizenship," Academy of Management Journal, Vol. 26, pp. 587-595, 1983.

[24] D. W. Organ, “Organizational citizenship behaviour: It's construct clean-up time," Human Performance, Vol. 10, pp. 85-97, 1997.

[25] P. Blau, "Exchange and power in social life," New York: Wiley, 1964.

[26] A. W. Gouldner, "The norm of reciprocity: A preliminary statement," American Sociological Review, Vol. 25, pp. 161-178, 1960.

[27] B. Schyns and K. Sanders, "In the eyes of the beholder: Personality and the perception of leadership," Journal of Applied Social Psychology, Vol. 37, pp. 2345-2363, 2007.

[28] D. M. Rousseau, "Psychological contracts in organizations: understanding written and unwritten agreements," Newbury Park, CA: Sage Publications, 1995.

[29] A. S. Tsui, J. L. Pearce, L. W. Porter, and A. M. Tripoli, "Alternative approaches to the employee-organization relationship: Does investment in employees pay off?" Academy of Management Journal, Vol. 40, pp. 10891121, 1997.

[30] A. A. Nerkar, R. G. McGrath and I. C. MacMillan, "Three facets of satisfaction and their influence on the performance of innovation teams," Journal of Business Venturing, Vol. 11, pp. 167-188, 1996.

[31] D. Duchon, S. G. Green, and T. D. Taber, "Vertical dyad linkage: A longitudinal assessment of antecedents, measures and consequences," Journal of Applied Psychology, Vol. 71, pp. 56-60, 1986.

[32] O. Janssen and N. W. Van Yperen, "Employees' goal orientations, the quality of Leader-Member-Exchange, and the outcomes of job performance and job satisfaction," Academy of Management Journal, Vol. 47, pp. 368-384, 2004.

[33] R. Eisenberger, R. Huntington, S. Hutchinson, and D. Sowa, "Perceived organizational support," Journal of Applied Psychology, Vol. 71, pp. 500-507, 1986.

[34] G. Graen, J. B Orris., and T. W. Johnson, "Role assimila- 
tion processes in a complex organization," Journal of Vocational Behaviour, Vol. 3, pp. 395-420, 1973.

[35] C. R. Leana, "Predictors and consequences of delegation," Academy of Management Journal, Vol. 29, pp. 754-774, 1986.

[36] L. M. Lapierre, R. D. Hackett, and S. Taggar, "A test of the links between family interference with work, job enrichment and Leader-Member-Exchange," Applied Psychology: An International Review, Vol. 55, pp. 489-511, 2006.

[37] H. K. S. Laschinger, N. Purdy, and J. Almos, "The impact of Leader-Member-Exchange quality, empowerment, and core self-evaluation on nurse manager's job satisfaction," Journal of Nursing Administration, Vol. 37, pp. 221-229, 2007.

[38] N. Torka, M. Van Riemsdijk, and J. C. Looise, "Werkgeversbetrokkenheid," [Employers commitment] Tijdschrift voor Arbeidsvraagstukken, Vol. 23, pp. 45-59, 2007.

[39] J. S. Adams, "Toward an understanding of inequity," Journal of Abnormal and Social Psychology, Vol. 67, pp. 422-436, 1963.

[40] J. S. Adams, "Inequity in social exchange," In L. Berkowitz (Ed.), Advances in experimental social psychology,
New York: Academic Press, Vol. 2, pp. 267-299, 1965.

[41] M. Tremblay, B. Sire and D. B. Balkin, "The role of organizational justice in pay and employee benefit satisfaction, and its effects on work attitudes," Group and Organization Management, Vol. 25, pp. 269-290, 2000.

[42] E. L. Deci, "Effects of externally mediated rewards on intrinsic motivation," Journal of Personality and Social Psychology, Vol. 18, pp. 105-115, 1971.

[43] B. L. Rosenbaum, "Leading today's technical professional," Training and Development, Vol. 45, pp. 55-66, 1991.

[44] S. R. Barley, "Technicians in the workplace: Ethnographic evidence for bringing work into organization studies," Administrative Science Quarterly, Vol. 41, pp. 404-441, 1996

[45] D. Guest, "HRM: The workers' verdict," Human Resource Management Journal, Vol. 9, pp. 5-25, 1999.

[46] A. N. Garman and P. W. Corrigan, "Developing effective team leaders," New directions for Mental Health Services, Vol. 79, pp. 45-54, 1998.

[47] D. M. Rousseau and Y. Fried, "Location, location, location: Contextualizing organization research." Journal of Organizational Behaviour, Vol. 22, pp. 1-13, 2001. 